\title{
Article
}

\section{"I am Done with Toys!" - The Benefits, Joys and Risks of Creativity and Innovation in Graduate Writing Support}

\section{Zoë Jones ${ }^{1}$}

Learning Enhancement Team, University of East Anglia, UK

Nonia Williams

Learning Enhancement Team, University of East Anglia, UK

\section{Abstract}

Writing is a necessary part of the graduate student's journey; it can also be a stressful and frustrating one that leaves students feeling "stuck" and disheartened. In this article we discuss four playful and alternative strategies that aim to free-up and inspire our graduate writers: our use of shape cards, LEGO®, walking tutorials, and yoga and meditation for writing. Through a combination of reflection on experience, initial primary research, and engagement with wider discussions, we demonstrate the benefits and joys of our creative and innovative writing support work. However, we also acknowledge that such techniques involve risks and challenges, and they certainly will not suit every graduate writer: as one of our students put it, "I am done with toys!" Nevertheless, as this article demonstrates, such practices have a real potential to support, empower, and deepen graduate student writing.

\section{Introduction}

This article emerges out of our shared passion for using playful, visual, and innovative techniques to help graduate writers overcome blocks and re-engage with their writing in a way that we believe can be both productive and joyful. The use of innovative approaches to help graduate students develop their writing feels timely: evidence of students' struggles to produce the writing expected of them is not hard to find. Blog posts referring to a lack of productivity, alongside stress and depression (Corrigan, 2017), with negative terms like the "thesis prison" (Mewburn, 2015, para. 4), and "imposter syndrome" (Franklin, 2017, para. 2) are produced by graduate writers around the world. This is not surprising, since research has revealed feelings of anxiety, low self- 
Volume 28, 2018

http://journals.sfu.ca/cjsdw

efficacy, and isolation specifically associated with the writing process (Bowstead, 2009; Huerta, Goodson, Beigi \& Chlup, 2016). These negative feelings among graduate writers are echoed in Sword's (2017) research where female PhD students were three times more likely to feel negative about their writing than other writers who participated in her study.

The stresses felt by graduate writers in relation to writing fits into the wider context of concerns for student mental wellbeing. In both Canada and the UK there has been talk of a mental health crisis on university campuses, as record numbers of students fail to complete their courses (Lumau, 2012; Marsh, 2017). Graduate students may be vulnerable to a number of pressures that can negatively impact studying: moving away from home, family and friends, and perhaps studying in an unfamiliar culture and language (Gani, 2016; Mental Wellbeing in Higher Education, 2015). On top of these pressures, graduate students will need to cope with producing work at a higher level of study, and for those on Masters programmes, the pressure of making the adjustment in a very short timeframe due to the structure of their courses. These are difficult circumstances for producing writing to share with "experts" in a field, and on which students will ultimately be assessed.

Addressing the needs of these students can, therefore, be particularly challenging for writing development tutors. Working with students with varying levels of experience, from different disciplinary backgrounds, and at different stages of their writing process is no mean feat. This is often a situation that we face as learning enhancement tutors working at a medium-sized mainstream university in the East of England, UK. In this role, we help students at all levels to develop their academic writing, alongside supporting other areas of study such as reading, notetaking, delivering presentations, and time management. Our contact with students takes the form of group workshops as well as individual tutorials.

This article discusses some of the practices we have been developing since 2014, which particularly aim to support Masters level and PhD students' writing in response to some of the challenges of graduate writing summarised above. Firstly, we outline our use of two techniques that encourage students to try something new by using visual and playful approaches to develop their writing: picture cards and LEGOß. In the second half, we describe two innovative techniques that encourage students to attend to their bodies to facilitate the writing process: walking tutorials, and yoga and meditation. In explaining our rationale for using these techniques with graduate writers, we aim to demonstrate how such creative and innovative strategies might be particularly well-placed to support students' resilience, confidence, and flexibility. The innovation of such practices can also, as we discuss, help students to reflect, see more clearly, and think more deeply about the writing process. However, it is also necessary to acknowledge that 
Volume 28, 2018

http://journals.sfu.ca/cjsdw

these techniques can be risky for both graduate students and writing tutors alike, since, as our title suggests, "everyone seems to have different loves-and-loaths" (Haas, 2014, "The Workshop Sessions," para. 4).

This paper has provided us both with the opportunity to reflect on our practice. While our work in this area has not yet taken the form of a developed or sustained research project, since autumn 2016 we have begun to work with initial data and evidence, with the aim of assessing some of the effects of our practice. The data we discuss below includes graduate students', tutors', and lecturers' observations about the activities and practices under discussion. These have been collected through personal communications by email following individual tutorials and workshops, which range in size from 6 participants to over 30 . Some of our material is necessarily anecdotal, and the data we have to date is a relatively small sample of feedback from no more than 50 participants. Originally, feedback was sought as part of our continued professional development in order to inform and improve our practice. However, once our work began to take the form of a pilot project, we gained full permission for all data included in this paper; in addition, all student/lecturer comments have been anonymised. While the collection of feedback has so far been informal and on a small scale, for us it forms the beginning of an action research project (McNiff, 2013) about the effectiveness of such techniques in terms of their potential impact on graduate student writing.

In presenting our experiences, this article aims to explore and provide some answers to the following questions: How might playfulness, visual strategies, and alternative or innovative approaches be important for graduate writing development? What are some challenges with using these approaches? What are some successes?

\section{Keep learning}

While graduate students will engage with new material in many aspects of their learning, when it comes to developing their writing, our experience is that they tend to fall back on old techniques, such as reading and re-reading. They do so even when they do not feel that these strategies are particularly helpful or lead to success. Trying new approaches can help graduate writers to become "unstuck" and increase their confidence as they feel that they are in control of the writing process.

The benefits of experimenting with ways to develop writing may well be attributed to the fact that trying new activities is generally good for boosting self-esteem and confidence. In a report commissioned by the UK government to find ways to improve the nation's wellbeing (Aked, Marks, Cordon \& Thompson, 2008) the authors advise people to "Keep Learning," by which they 
Volume 28, 2018

http://journals.sfu.ca/cjsdw

mean, "Try something new. Rediscover an old interest... Set a new challenge," claiming that this will "make you more confident, as well as being fun to do" (p. 8). Meanwhile, with particular reference to graduate writing, Thomson (2016, para. 10) highlights the need for academic writers to develop "a repertoire of strategies" for writing since "there will almost inevitably be occasions when you have to try other things, to modify what you do, to improvise". Haas (2014, "The Workshop Sessions", para. 7) advocates the provision of "a wide range of strategies" within graduate writing workshops to suit the needs of different writers. Sword (2017) also emphasizes the need for successful writers to view their writing through the lens of ongoing learning. The "artisanal" aspect of writing which she identifies involves creativity, craft, and artistry (Sword, 2017, p. 4). In our workshops and tutorials, we encourage graduate students to "keep learning" about techniques which can help them to enhance the texts they produce in a way that we feel encapsulates some of those notions of creativity, crafting, and artistry.

In the first half of this article, we consider the usefulness of two creative techniques: a set of "shape" pictures and LEGO®. These approaches are visual, thereby providing "an important and helpful interface between thinking and writing" (Badenhorst, Moloney, Rosales \& Dyer, 2016, p. 338). There is also an element of play involved, particularly with the use of LEGO $₫$, which allows students to "look into their thinking" (Hyerle 2008, p. 154), while enjoying activities related to the writing process. This enjoyment can lead to a state of "flow" (Csikszentmihalyi, 2014), which involves a decrease in writing-related anxiety and regaining of control for the graduate writers.

\section{What shape is your writing?}

Graduate writers may have gathered ideas from the literature or from their own research, but still be unsure of how to begin turning these into a coherent text. Feelings of uncertainty about where to begin can be anxiety-inducing, particularly since the structure of writing is less likely to be prescribed than it was at undergraduate level. To help students to navigate the early stages of draft writing, we have developed a set of fifteen cards featuring different pictures which we share with students to ask them, "What shape is your writing?" or "What shape do you think your writing is going to be?" Students are intrigued by being asked these questions because they have not usually been asked about the shape of their writing before. By starting with a shape, students can begin to think about how their ideas might relate to one another. Sword (2017) points out that successful academic writers "are makers and shapers of language, in much the same way that weavers are makers and shapers of textiles" (p. 57). The shape cards make it easier to communicate that there might be a variety of ways in which graduates could make and "shape" their writing. Students can be given the freedom to adapt one of the shapes (see Figure 2 for an 
example of this) or to create their own, which seems easier once they have seen the examples on the cards. Barnett (2016, p. 8) equates academic writing to designing a building with the skill of an architect, leading the reader "from room to room" through a coherent text. The selection, rejection, or adaptation of different shapes from the cards allows graduate writers to become more confident as they take responsibility for "shape," and gain a growing sense of themselves as the architect of their writing.
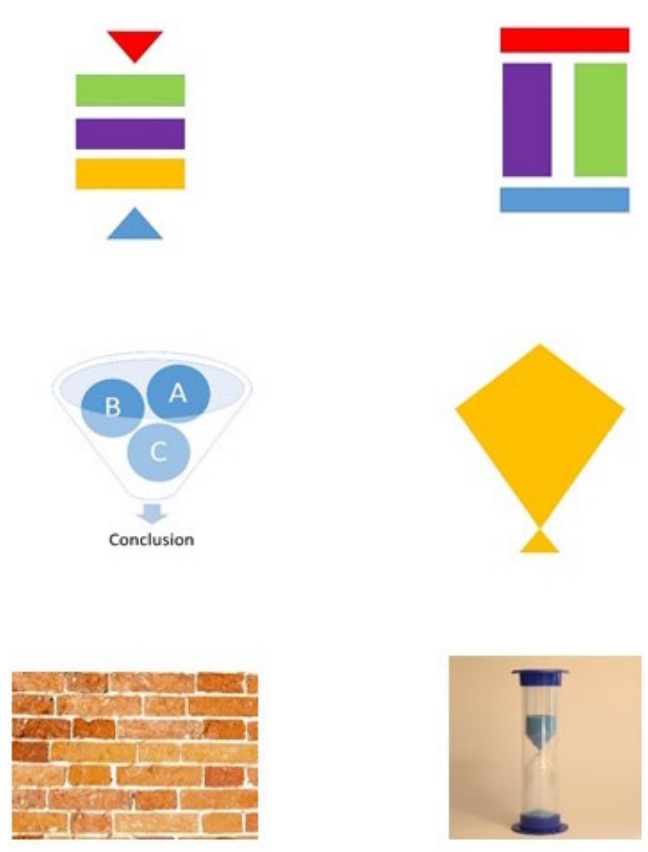

Figure 1: Examples of shapes from our "What shape is your writing?" cards

The cards can also be used to enable graduate writers to visually consider the "shape" of a draft of writing in order to gain new perspectives. When students have been working on a piece of writing over a period of time, it can be difficult for them to move it forward or respond to feedback from their supervisor. This block can be a consequence of over-reliance on text and verbal discussions as a means of enhancing draft writing (Thomas, Place \& Hillyard, 2008). This was certainly the experience of one graduate Humanities student. The shape cards enabled her to make progress with writing during her Masters programme, and she went on to use them while writing her dissertation. Figure 2 shows how the student adapted one of the shapes on the cards to develop the structure of a section of her dissertation. She was struggling to make sense of the vast amounts of information at her disposal, and found it difficult to put these ideas into a 
Volume 28, 2018

http://journals.sfu.ca/cjsdw

coherent order. Other techniques, such as freewriting, were not working. The tutor suggested that she look through the cards to see if they suggested a shape which she could work with. She settled on a shape and began to think about how her ideas might relate to it. She became animated and, with guidance from the tutor, began to sketch out a plan on the whiteboard. The novelty of this technique-being given a new perspective from which to consider her work-allowed the student to approach what felt like an overwhelming task with renewed enthusiasm. It was a rewarding experience to see her reconnect with the joy she felt for her topic and to witness her become "unstuck":

[The tutor] encouraged me to visualise the "shape" of my essay before I began to write...and I found this really helped me to understand how the different points slotted together. She encouraged me to write essay plans in a kite shape...I no longer stare blankly at a screen for hours at a time, nor do I find myself so panicked that I cannot begin to write anything down. (Email feedback from Humanities Masters student, June, 2016)

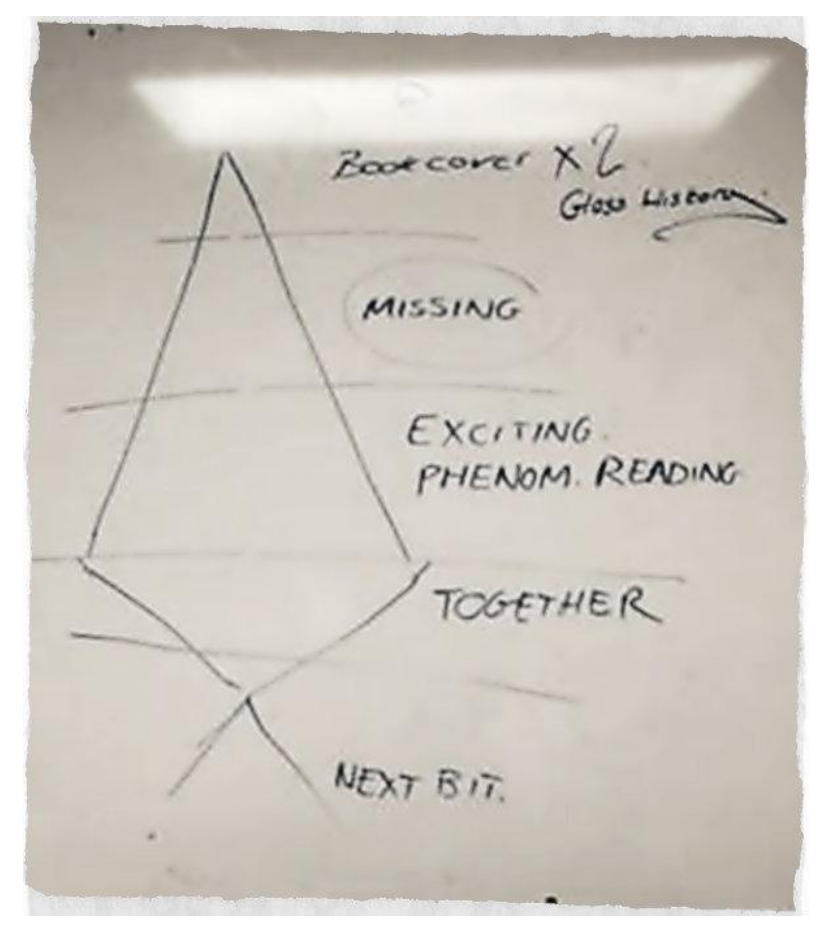

Figure 2: Humanities Masters Student's adapted "shape" used to develop a piece of writing

The shape cards were produced as part of a summer project in 2014, following discussions with Simon Andrews, a Specific Learning Difficulties tutor in our team. Simon works with students with conditions such as dyslexia and Attention Deficit Hyperactivity Disorder. Our conversations revealed shared successes with using shapes and pictures to help students develop 
Volume 28, 2018

http://journals.sfu.ca/cjsdw

their writing. Some of the pictures and shapes we were using were similar, while each of us had our own particular favourites. It was revelatory to discover this shared practice and we decided to produce a set of cards that brought together the shapes we had been using to help students visualise their writing. Some of the shapes correspond to the way students will expand on points or focus in on them, or have blocks of colour which might represent the number of points or themes that might be included. Other shapes can be interpreted metaphorically: "The bricks in the wall represent the points I will make in this section, I need to work out how to cement them together," for example. We designed and produced the cards ourselves, and have distributed them within our institution to interested members of staff and students. Subsequently, we have become aware that the idea of "shaping" writing is discussed in some study skills books (for example, Creme \& Lea, 2008; Ridley, 2008). Wellington, Bathmaker, Hunt, McCulloch and Sikes (2005, p. $80)$ propose three shapes which are similar to those included in our cards: the funnel (see Figure 1), patchwork, and concentric circles (we use a picture of a tree's annual rings). While we have included "common" shapes like these, our cards offer a wider range of colourful shapes and pictures. The range has evolved from our conversations with students and lecturers, as well as with each other, about what kinds of shapes seem to relate to different pieces of writing. We will continue to add new shapes as they emerge through our writing development work.

Initially the cards were used in tutorials when discussing an individual student's plans for a piece of writing, or to facilitate a discussion around how work could be edited to make it more coherent or cohesive. This could form the basis of a whole 50-minute individual tutorial. Once our confidence in the usefulness of the cards had grown, they were introduced in Personal and Professional Development workshops with PhD students, and writing workshops for Masters students. Participant numbers for these workshops range from 5 to 30 students. Students have used the cards to discuss in pairs or small groups which shape they think a writer has used, or the pros and cons of using different shapes for their own writing. It is possible to use the cards in workshops for brief discussions around potential structures for writing, or for a lengthier activity linked to other activities such as outlining or freewriting.

As well as providing graduate writers with a new strategy to add to their repertoire for getting their writing done (Thomson, 2016), the cards add a visual element that would otherwise be missing from their experience of the writing process (Thomas et al., 2008). Hattie (2012, p. 101) advocates the use of visual and multimedia teaching materials since they "provide richer representations than can a single medium." Students like handling the cards (which are shiny and colourful) and this kinaesthetic element seems enjoyable, contradicting the myth of graduate writing as a dull pursuit. Finer, Shelly, Gatta, Warmington and Alawdat (2016) find that low-tech 
Volume 28, 2018

http://journals.sfu.ca/cjsdw

approaches such as this not only allow for interactions which are conducive to learning, but also allow students "to recontextualize their understanding of hi-tech course content...in a low-tech context" (p. 60). More specifically, making complex concepts understandable and digestible for their readers is an important skill for graduate writers. Previous research has discussed the use of diagrams and images to facilitate classroom discussion, generate creative thought which is more tangible, and prepare students for writing (Badenhorst et al., 2016; Buckley \& Waring, 2013; Hyerle, 2008; Wellington et al., 2005). The shape cards allow students to think and then talk about often abstract ideas in a more concrete way, a helpful stage towards representing these ideas in texts for the students' intended audience. Furthermore, the cards enable a shared understanding with peers or tutors, allowing the writing process to be a dialogic, and developmental, project.

\section{Playing with $L E G O \AA$, seriously?}

Perceiving how much students enjoyed the visual and kinaesthetic element of the shape cards led Zoe Jones to explore the idea of using 3D models to encourage students to consider the structure of their writing. Zoe experimented with different kinds of building blocks before coming across the idea of using LEGO $囚$, which she subsequently discovered was being used in the Higher Education context following the LEGO® Serious Play® method (outlined by Nerantzi \& McCusker, 2014). While LEGO® has been used for writing development before, examples in the literature suggest that this tends to be to generate ideas for reflective writing (Nerantzi \& McCusker, 2014; James, 2013). Although there are some similarities in the way we have used LEGO ${ }^{\circ}$ to develop writing, what is different about our use is that we specifically address structure in extended pieces of research-based writing. Since the academic year 2015-2016, our tutors have used LEGO® for writing development with both PhD and Masters students. LEGO® can be used to encourage reflection on the structure of a piece of writing from the macro (overall structure) to the micro (paragraph) level. We have also used it to encourage students to think about the writing process itself.

In our introduction, we discussed some of the factors that can negatively affect graduate students' ability to write. It can seem risky asking students under such pressures to take time out from the serious business of analysing their data and actively producing writing to engage in an activity involving LEGO®. However, our experience suggests that there is potential for such activities to benefit graduate writing. These benefits might not always be immediately obvious, but make it worth persuading students to take the risk. The chance to work creatively and with their hands is an opportunity that graduate students may not often get, but many seem to enjoy. 
Volume 28, 2018

http://journals.sfu.ca/cjsdw

Providing students with multi-sensory learning activities is recommended in the literature (Hattie, 2012, p. 101), and in particular students with Specific Learning Difficulties may benefit (James, 2013). As with the shape cards, using LEGO® introduces a visual aspect that enables students to "look back on their ideas, refine them, and share them with others to get feedback" (Hyerle, 2008: p. 156). Being able to talk about their research effectively should enable students to write with more clarity, confidence, and perhaps even enthusiasm, having rediscovered what is central to their research (Elbow, 2012; Race, 2015). This is especially pertinent in the case of graduate students, who may well spend much of their time writing in isolation. Certainly, LEGO® activities with PhD students can re-energise those who seem jaded, aiding animated discussions about their topics and their writing. James (2013) also finds that international students are receptive to using $L E G O ®$ due to its universal availability (a point echoed by Badenhorst et al. (2016) with regards to visual approaches), and certainly anything which can level the playing field for the many graduate students who are non-native speakers of English would seem desirable. In a recent Thesis Writing Workshop, one participant commented that he felt that students were more willing to speak about their research topics after using LEGO®. Graduate students are often engaged in writing about complex subjects, and it seems to us that something about the simplicity of LEGO ${ }^{\circledR}$ bricks, coupled with the playful element, allows them to think, talk, and (hopefully) go on to write about these complex topics, in a more lucid and straightforward manner.

Although we have used LEGO® with individual students in tutorials, it seems to work best in a workshop scenario. This is probably due to students in workshops feeling less self-conscious about "playing" when everyone else is doing the same. In addition, in our experience, LEGO® activities take time, requiring at least an hour, and at our institution graduate writing workshops are 2-3 hours long. We tend to use LEGO ${ }^{\circledR}$ with smaller groups of students, mainly to ensure that we have enough bricks to go around. Students work in pairs or groups of up to 6, depending on the overall size of the group. They are asked to build a model that represents something to do with their writing: the structure of a chapter or thesis, for example. They can use the LEGO® to represent the size or "shape" of elements in their structure, use pieces metaphorically to represent concepts they are going to write about, or to consider how different ideas might connect together in their writing. Students often add figures or faces to think about where their supervisor might fit into the process of producing specific parts of their texts. After building models students "share stories" (Nerantzi \& McCusker, 2014, p. 4) about them and respond to questions from the tutor or other students. This activity can then be followed up with other writing activities, such as creating an outline or freewriting about the content of a chapter. 
Volume 28, 2018

http://journals.sfu.ca/cjsdw

A particularly successful example of using LEGO® for planning writing was with a group of students on a Management course. They had just started to think about the overall structures of their Masters dissertations. After some lead-in activities, we asked them to use LEGO® to build what they thought their structures might "look" like (Figure 3 below). Using LEGO@ with this group of students felt risky, because it was difficult to gauge whether they would enjoy creative activities, which seemed unlikely to have featured in their courses before. However, as soon as the students saw the LEGO® they became animated and excited about using the bricks. Afterwards, one participant commented on the usefulness of the activity:

It helped me personally for example to use bigger chunks of LEGO@ for the main parts like the literature review, and smaller pieces for parts such as the introduction. This helped me to feel more confident as I had a better idea of how to structure the dissertation. (Email feedback from workshop participant, March 2017)

The lecturer for the dissertation module was present during the workshop and also gave a positive evaluation of the activity, feeling that "The LEGO® was great-it helped them to think about the structure and start focusing on the dissertation process" (Email feedback from Management lecturer, March 2017). The perceived risk seemed to have paid off here, enabling students to approach a potentially daunting piece of writing with a sense of adventure and fun, and to engage in helpful conversations with their peers, lecturers and tutors. The result was an increased confidence of how to approach the writing task going forward.

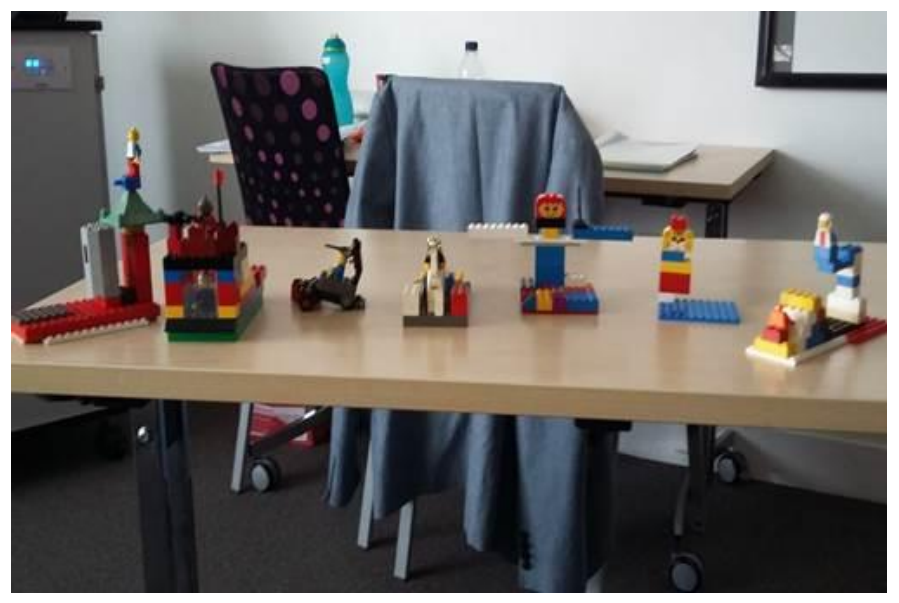

Figure 3: LEGO ${ }^{\circledR}$ models built by MSc Management students to represent their dissertation structures 
Volume 28, 2018

http://journals.sfu.ca/cjsdw

While the use of LEGO ${ }^{\circledR}$ to develop graduate writing has been well-received by most students and academics, it should be pointed out that other students have felt reluctant to use what might be seen as a simplistic technique:

At first I was a bit surprised when I saw we were going to be using LEGO $®$, as I haven't used LEGO® since I was a child!

(Email feedback from Masters in Management student, March 2017)

LEGO®s are fine for first years, I suppose, but I am done with toys!

(Email feedback from Postgraduate Research student, May 2017)

As these student quotes suggest, some of the initial resistance stems from the idea of it being "childish." The extent to which students find LEGO® helpful might also depend on what stage of their writing they are at, whether they are still "playing around" with ideas, or at the later stages of a writing process, for example.

The use of playful pedagogies in higher education is, however, nothing new (James, 2013; Nerantzi \& McCusker, 2014) and their potential for learning is reasonably well established: "We all learn an immense amount in early childhood, seemingly effortlessly, by playing. Then all too soon, learning seems to be relegated to "work." This is tragic and unnecessary!" (Race, 2015, p. 9). In our experience, graduate students who are at first reluctant, and even those who remain unconvinced about its usefulness, can still find using LEGO® to think and then talk about their writing enjoyable. Even the student who supplied the second quote above admitted she had found the activity fun. Indeed, to mitigate for any potential resistance to using a playful medium like LEGO ${ }$, we are often explicit with students about our pedagogical motivation. We also discuss past experiences we have had with students who have successfully used LEGO@ to facilitate discussions about their writing. It is helpful to make the point to students that the LEGO® is just one of a range of activities in which they will be able to engage, and of course nobody is forced to participate, play is always optional by its very nature (De Koven, 2017). In fact, our experience is that it is extremely rare for a student to completely opt out of a LEGO ${ }^{\circledR}$ activity, but when this has happened they have still observed others building models related to their writing and been able to engage in conversations about these.

It is difficult to know whether using shape cards and LEGO® has a direct impact on the quality of the students' writing (and it might well be difficult for the students themselves to know if this is the case). However, the fact that both techniques can "vitalise" workshops (as one participant recently commented) suggests that trying creative techniques such as these can benefit graduate 
Volume 28, 2018

http://journals.sfu.ca/cjsdw

students. Crucially, both are low-tech, taking students away from the screens that might be blocking them from making progress, and turning their texts into something tangible. If students like working with their hands or engaging visually with their learning, they might particularly enjoy these techniques. We believe these activities help graduate students to develop their writing, alongside an enhanced sense of confidence, by expanding their repertoire of strategies for managing the writing process, helping them to actively engage with their texts, and making it easier to discuss their writing with other people by making the abstract more concrete.

\section{Embodied writing support}

In our work with graduate student writers, we have more recently (since autumn 2016) developed two practices that aim to further develop the kinaesthetic aspect of our play with shapes and LEGO®: these are; "walking tutorials" and the use of yoga and meditation at writing retreats. The writing retreat suggests walking tutorials-the student and tutor go for a walk together-while the yoga and meditation work is offered as an optional session during our graduate writing retreats. Our recent work in this area has been developed alongside wider discussion around "Embodied Writing Support," following Nonia Williams' attendance at the Higher Education Academy (UK) event of the same name in June 2016. The range of speakers and practices under discussion there confirmed our belief that attending to the body can play a significant role in graduate writing development work. In addition, Aked et al.'s (2008) report (introduced in the "Keep learning" section above) identifies physical activity as essential for wellbeing. They encourage people to "Be Active," saying "Go for a walk or run. Step outside," because "Exercising makes you feel good" (p.8). This connection between physical activity and wellbeing provides one way of thinking about why physical activity for writing might be particularly helpful for supporting graduate students' self-efficacy and feelings of positivity around the writing process.

Indeed, the negative effects of forgetting the body when writing have recently been discussed in a blog post for the Thesis Whisperer ("Your body is as important as your mind," May 2017). There, Paul T. Corrigan reflects on his experience as a graduate student, and specifically on what happened to his learning when he squeezed exercise out of his routine in the hope that this would create more study time. The result, of course, was that, rather than freeing up more time and making Corrigan more productive, the lack of attention to his body and bodily movement had a negative effect. More specifically, instead of seeing exercise as separate to the learning and writing process, in the sense of bodily activity then stimulating the mind, Corrigan concludes that exercise is a fundamental "part of studying": 
How could an hour of walking be more useful for learning than an hour of reading or writing? It's simple.

Your brain is part of your body. When you neglect your body, you neglect your brain. When you take care of your body, you take care of your brain. (Corrigan, 2017, para. 12, italics in original)

The writing development practices we discuss below concur with Corrigan's observations. These practices encourage graduate students to consider the physical body as central in the writing process. In this way, our students understand that moving and focussing on the body can help get writing moving too; it can help them overcome blocks, loosen up thinking, open new directions, or refocus the mind. This shift towards a more explicit focus on mind and body together can also help alleviate tension or anxiety around the writing process and enable a fresh and positive way of working with the tutor beyond the conventional tutorial or classroom space. However, as with the creative strategies of using shapes and $L E G O 囚$ that we have discussed above, such practices can be risky, and the idea that the physical body plays a wider and deeper role in writing than merely the activity of putting words on a page is challenging for some students. It can also be liberating, because it acknowledges that the graduate writing process is long, multifaceted, often messy, and sometimes blocked and in need of freeing up. In the second half of this article, we discuss our walking tutorial, and yoga and meditation for writing work with students, to tentatively suggest some of their benefits. These more recent practices of ours are in early pilot stages, but the positive potential, as well as some of the challenges, are already apparent.

\section{Walking tutorials}

So far, our experience suggests that walking tutorials may be particularly beneficial for graduate students, whose long and complex writing assignments-dissertations and $\mathrm{PhD}$ projects-mean that we work with them over a period of time. The complexity and particular intellectual demands of sustained writing mean that, as we suggest above, these students need to develop a range of strategies and tools for supporting and developing their writing as well as for nurturing and sustaining their confidence, flexibility and resilience.

We have been using "walking tutorials" as a way of working with graduate students on their writing since spring 2017. In the walking tutorial itself we, tutor and student, spend part (usually around 20 minutes) of a 50 minute one-to-one session walking together outside the tutorial 
Volume 28, 2018

http://journals.sfu.ca/cjsdw

space. The activity provides an alternative space for talking, thinking about and generating writing, which can work to refresh the writing process. As one participating student put it:

I was hoping that being in a different environment would encourage me to think differently, because the way I was approaching my writing clearly wasn't working. Sitting at my computer for most of the day left me feeling stuck, and I was hoping this would get me out of that particular rut. (Email feedback from Humanities Masters Student, June 2017)

The walking tutorial session begins with a goal-setting discussion of what aspects of their writing the student would like to focus on during the walk; these provide the tutor with ideas for prompts and questions. This initial discussion in the tutorial space includes attending to and completing a "walking tutorials agreement" which details how the tutorial will work, including, for example: making sure that both parties feel comfortable; reminding the student that they can record the discussion; confidentiality; making sure both parties are appropriately dressed. Tutor discretion is key, and we are careful to consider whether or not walking tutorials are appropriate for individual students; whether, based on which aspects of the writing process the student is struggling with, walking for writing might benefit them. The tutor must also, of course, feel comfortable working with the student in this particular way. Both parties must feel that the potential challenges of innovation-in terms of the student's receptivity or openness, as well as the tutor's own confidence and comfort with the practice-are in this case worth risking. Indeed, on a more practical note, concern for the safety of both parties underpins the student agreement that we have devised (Appendix 1), which the student completes before the walk takes place, and the design of the walking tutorials route. These are underpinned by risk assessment considerations and we have completed the appropriate forms in order to meet university regulations and requirements. If tutor and student are comfortable, and once the agreement has been read through and signed, the walk begins. Afterwards, tutor and student return to the tutorial space together to reflect upon and discuss the experience. This immediate reflection comes out of our intention that the effect of the walking tutorial is both that the student's writing is moved along in some way, but also that the student is able to think of the benefits of walking as a way of thinking more deeply about the learning process itself.

To date we have trialled only a handful of walking tutorials, but the response from participating students has so far been positive. Feedback focuses on the informality of "going for a walk" together and how this has enabled a freer, more relaxed discussion, as well as of how productive and helpful the experience can be for generating ideas and overcoming writers' block 
Volume 28, 2018

http://journals.sfu.ca/cjsdw

and the sense of "stuckness." One participant said that although it was a little awkward at the start, they soon felt comfortable and absorbed in the activity. In this tutorial, both tutor and student were particularly struck by how the landscape structured the discussion. For example, while still surrounded by the university buildings, the tutor noticed that conversation was more informal; there seemed to be a shift towards more focussed discussion once they were walking in open space. This suggests that moving through different physical environments-different spaces and places-might facilitate and enable participants to shift into different modes of thinking. Another benefit of the walking tutorial is the way that it requires tutor and student to be side-byside rather than face-to-face. This moving alongside each other rather than sitting opposite, the lessening of focus on eye-contact, was an unexpected positive outcome of the walking tutorial for one student, who commented that:

walking side by side was surprisingly helpful—though I'd never felt uncomfortable in face to face tutorials where we sit opposite each other, this felt a lot more informal. I was able to say things without worrying about the correct terminology. (Email feedback from Literature Masters student, June 2017)

For this student, talking while walking alongside her tutor noticeably freed up her speech. Rawle (2017) similarly comments on the benefits of walking side-by-side and how this can enable different kinds of speech between tutor and student in her discussion of "walking office hours" at the University of Toronto.

Furthermore, the experiences of students participating in our pilot coincides with claims made in wider critical discussions of walking and writing. It is, of course, well known that many novelists and philosophers-from Plato to Rousseau to Woolf-claim a close connection between walking and thinking/writing. At the beginning of her case for embodied writing support, Clughen (2014, p.292) reminds us that "[o]ne of the most commonly identified expressions of the physicality of writing is the felt reciprocity often highlighted between the activity of walking and writing." Other recent work in other fields such as psychology and neuroscience also argue for a close and symbiotic, or even simultaneous, connection between bodily and mental movement and activity. For example, Oppezzo and Schwartz's (2014, p.1142) analysis of four psychological studies assessing the relationship between walking and creative ideation concludes that: "People have noted that walking seems to have a special relation to creativity ...The current research puts such observations on solid footing" (The pun is surely intended here, although what it also highlights are the ways in which many of the common or even forgotten metaphors in language 
Volume 28, 2018

http://journals.sfu.ca/cjsdw

are, as Lakoff and Johnson (1980) as well as many others since have pointed out, "grounded" in the physical, material world). Oppezzo and Schwartz (2014) note that the positive effects of walking extend to "when people sit down to do their creative work shortly after" (p.1142) which is corroborated in student feedback on the experience of walking tutorials: "When we came back inside, I was able to write down points on my essay-some which I had half-worked out in my head, some of which I'd only thought of while walking - in a helpful order" (Email feedback from Literature Masters student, June 2017). Such material confirms the idea that physical activity stimulates writing by freeing up thinking - in short, that walking is good for writing-but there remains a sense of body and mind as separate. In these examples the writing, described above by Oppezzo and Schwartz (2014) as the activity of putting words on the page, happens as a result of but after the walking itself.

\section{Meditation and yoga for writing}

Our recent work (also since spring 2017) using yoga and meditation for writing takes the motivation behind the walking tutorials, to acknowledge the role of the body in the writing process, even further. Here, our practice concurs with Corrigan's (2017) claims above that the brain is part of the body, and therefore that, when it comes to writing (as with other cognitive activities), bodily activity might be considered as one and the same as mental activity. This notion of interconnectedness informs both the reasoning behind including yoga and meditation sessions during our day-long graduate writers' retreats, and the form they take. The retreats themselves are a relatively recent innovation at our university, based on research which suggests that social writing boosts productivity as well as a sense of shared endeavour, enabling students to overcome what can feel like the "lonely struggle" of the graduate writing process. The system and structure of our retreats draw upon Rowena Murray's work in this area (see, for example, Writing in social spaces: a social processes approach to academic writing, 2014).

Our writing retreats take place in space within the university away from where students usually work, and they are encouraged to come with a clear sense of what they would like to work on as well as food to share-and we provide drinks. In this way, the retreat is clearly a workspace, but also an alternative space, one where we look after each other in the writing process by attending to our bodies with food and tea. We also attend to our writers' bodies by offering an entirely voluntary yoga and meditation session during the hour-long lunch break. This is offered as a fifteen- to twenty-minute combination of gentle physical movement and yoga poses, which finish with a five-minute meditation. The session was developed, in part, in response to students' complaints of feeling physically stiff and tense after a morning's intensive writing; it also comes 
Volume 28, 2018

http://journals.sfu.ca/cjsdw

out of our wide and longer-term interest in the benefits of using a wide range of kinaesthetic modes of learning with our graduate writers. Whereas-although this has not been our intention - the walking tutorials might be interpreted as the active body freeing up the (separate) thinking process, the yoga and meditation practices explicitly work to enable body and mind to come together. In this was we aim to cultivate fully embodied and immersed writing support that nurtures our graduate writers' feelings of clarity and positivity.

Insistence on the unity of body and mind in the learning process is widely prevalent in philosophical and critical discussions about how learning works and where it takes place. In neuroscience, for example, Doyle and Zakrajsek (2013) define the learning process in terms of the physical changes that take place when new connections between brain cells are made. More specifically, they argue for a direct biological connection between exercise and the increased release of neurochemicals and proteins, between bodily movement and learning. Here then, learning is always a physical, bodily thing. Tim Ingold's (2010) anthropological discussion of walking, breathing and knowing is particularly useful in connection with our work because of his insistence that: "Walking alone, then, is not the behavioural output of a mind encased within a pedestrian body. It is rather, in itself, a way of thinking and knowing" (p.135, emphasis added). The insistence here that physical movement is itself a form of knowing echoes the point made by Corrigan in the blog post cited above. The point is an important one for our work with yoga and meditation for writing, that forms or modes of thinking and knowing (and writing, we suggest) are situated in the body itself. Rather than the body as something separate that works to stimulate the mind, here the body itself is seen as intelligent and knowledge-producing. Ingold terms this symbiosis of body and mind "ambulatory knowing" (p.122), or "motional thought" (p.135). This desire to move beyond mind-body duality is picked up on and developed in Clughen's (2014) article, which insists on reciprocity and interconnectedness, making the claim in philosophical and feminist terms.

Much of our own practice of using yoga and meditation for writing has been inspired by Christy Wenger's (2015) Yoga minds, writing bodies: contemplative writing pedagogy. Wenger's book comes out of her work incorporating yoga into writing composition classes, based on her belief that this creates a learning experience where "embodiment becomes the means of knowing, feeling and making sense of the world" (p.9). She too, like Clughen, draws on feminist thought in her insistence on the body and mind as unified rather than dual. Wenger's point is that "we are our bodies, not just that we have them" (p.43) and that the "integrated practice of yoga and writing" (p.47) can be a powerful reminder of this. In particular, Wenger claims that yoga can help students overcome the idea that the body is problematic or a block to writing, to be more 
Volume 28, 2018

http://journals.sfu.ca/cjsdw

accepting of and compassionate towards their bodily reality. Thus, rather than wanting to escape, suppress, or flee the body, yoga can help the individual see the mind and body as working together. This works when we are absorbed in a yoga pose, and can be even more visible in the apparent stillness of sitting for meditation, where the focus is on the movement of the breath itself. For Wenger this is particularly important: "Because breathing rejoins our body and mind and urges them to work together for a common purpose, it is a helpful practice for writers who find their own bodies sources of distraction when attempting to focus" (p.170). In this way, while the walking tutorials can enable students to navigate their way out of stuck spaces, yoga and meditation encourage students' acceptance of wherever they are with the writing, by encouraging them to inhabit and explore "where they are right now," suspending criticism or judgement.

The yoga work we do with students does not currently include challenging poses-although it might—but a combination of heart and shoulder openers that expand the body, twists to nourish and free up the spine, and balance poses for focus and quietness. The balance poses have an extra benefit because they are tricky, and so we all wobble. This brings smiles and laughter, breaking the "seriousness" that is often perceived of as appropriate, but that can actually create tension and interfere with participants' ability to be immersed in the moment. The closing meditation consists of one of the scripts that Nonia Williams has written (and continues to edit and develop). These meditations have been composed especially for the writing body. The scripts open by bringing the individual's attention into their physical body, whether that attention is on the breath, on sound, or a body scan, before harnessing the attentiveness this brings to develop a writing intention for the rest of the day. This could be about the mood or feeling that the student will approach writing with, or about what they would like to get done in terms of the quantity or quality of work. It is significant that this is an "intention;" not something students can succeed or fail at, but a writing aim that comes out of remembering that mind and body are one.

Of course, the practice of yoga and meditation in the writing classroom is currently quite unusual, and there is an element of "risk" for students and tutors. It can be daunting to sit with your eyes closed, and moving the body into unusual postures and poses might make individuals feel self-conscious. This is why the sessions are entirely voluntary, and we always offer an alternative activity as well as, where possible, a separate space for those not participating to work on freewriting a prompt, or goal-setting in other ways. Like Wenger, our intention with this practice is "not to turn students into martial artists or yogis; rather, it is to show them what they can learn by paying attention to their bodies" (p.15). As with the LEGO® activities, some students do choose not to take part-indeed, some of our writing development colleagues are less than comfortable with the idea of yoga and meditation in the classroom. However, it has been 
surprising and pleasing how many students do choose to participate: more often than not, all (1015) of the graduate students participating in the writing retreat also take part in the yoga and meditation. Indeed, there is evidence to suggest that such practices are becoming more widespread; for example the incorporation of "pilates/yoga" into Queen Mary University's Thesis Boot Camp, and the notion that these sessions are beneficial in terms of recognising the role of "self-care" as being essential for sustaining writing productivity (Campbell, 2017).

Written and anecdotal participant feedback identifies students' feeling that the sessions encourage better concentration, and that attention to the physical body benefits their writing. We have not yet collected data on the detail and manner of such effects, but this is something we intend to research further. Feedback so far includes, for example, participants' sense that the yoga and meditation sessions "put things into perspective" and "stop me getting overwhelmed," that they remind students "to be grateful for the space in which to write" rather than seeing it as a chore (Email feedback from postgraduate students, June 2017). Participants also identify that the practice brings feelings of positivity, space and creativity into their writing process; that it refreshes their enthusiasm for writing. It is particularly encouraging that several participants say that they would like to use yoga and meditation for writing outside of and beyond the retreat. This is significant, because while the writing retreat is productive partly because it provides an alternative and communal space for writing, we also hope that some of what we offer there will become part of some of our graduate writers' toolkit beyond the retreat space. When we offer students the kinds of innovative and creative techniques that we have been discussing, we always encourage them to "try them at home." At the same time, we openly discuss the challenges of taking new practices back into a regular space where they may be writing alone. As part of our commitment to supporting this transition, Nonia has recorded our "meditation for writing" scripts as well as videoing yoga sessions, to create resources that are available for our students to use beyond the space of the writing retreat itself.

\section{In conclusion: we are not done with playing yet...}

We began this article by outlining some of the challenges that graduate writers face, and asking how playfulness, visual strategies and alternative or innovative approaches might help to free-up and energise their writing practice. We hope that, in describing, explaining, and considering the effects of our work using shapes, LEGO®, walking tutorials, and yoga and meditation for writing development, our readers have gained a sense of what we see as the real "benefits and joys" as well as the "risks" of using creativity and innovation in graduate writing support. 
Volume 28, 2018

http://journals.sfu.ca/cjsdw

Of course, the techniques we have discussed will not work for everyone. Thus, is it essential that students know they are being offered a "pliable" (Haas, 2014, "The Workshop Sessions", para. 7) range of tools for writing. We cannot offer strategies that will be useful for every writer every time, and we want students to feel comfortable enough to reject what is offered if they so wish. As the exclamation in our title suggests - "I am done with toys!"-we have experienced resistant graduate students, who have felt that creativity and play might have been useful at the start of their writing process, but not near the end when they want to "get on with it." With some groups, we have not felt comfortable with-not wanted to risk-yoga and meditation, or LEGOß. And, in our experience, innovative practice is always a risk: for us as teachers as well as for our students, especially when such strategies do not straightforwardly connect with the "serious" business of the graduate writing process. In addition, because of the sheer range of tools and strategies that any writer will adopt, it can be difficult to measure or quantify the impact of such techniques on the "success" of student writing.

However, what our data so far does show, is how such practices inspire graduate students to think more deeply about their writing process. The unusual experience of, say, drawing a shape, playing with $L E G O \AA$, or going for a walking tutorial, enables fresh and alternative perspectives on writing, encouraging students to "take notice" of their processes, and what works for them as writers. Practices like yoga and meditation encourage students to remember the body in the writing process, and to consider stillness, contemplation, and compassion as vital factors in what can otherwise feel like the overly busy or worryingly blank experience. Furthermore, all of the practices we have discussed here-from playful to meditative-encourage flexibility and openness in the students' thinking about writing. While such practices seem to offer a break from the "work" of writing, in our experience they actually deepen, widen, and liberate students' understanding of what the writing process is, and this in turn supports students' resilience, selfefficacy, and confidence. It is empowering for them to know that writing is about making informed choices, and that there are a range of tools they can use to move beyond "stuck" spaces.

What is more, as with the best kinds of practices, our work with graduate writers has invigorated and developed our own teaching and writing. Through further reflection and research, we aim to develop our practice to engage our students ever more actively and reflectively in their individual writing journeys; to further research the effects of using such practices with graduate students, and to consider how such effects might manifest in the writing itself. In this way, as our work with graduate writers moves towards a more "contemplative pedagogy" (to take from Wenger's (2015) title), we hope to continue to play with and create an ever widening range of "ways in" to writing. 
Volume 28, 2018

http://journals.sfu.ca/cjsdw

\section{Endnotes}

1. Correspondence may be addressed to Z.Jones@uea.ac.uk

\section{Appendix 1: Walking tutorial student agreement}

\section{LET Walking Tutorials}

Walking can be a really good way of literally putting your ideas in motion and loosening up writer's block. If you're someone who finds walking helps you generate ideas, and you would be happy to have part of your LET tutorial take place out of the building please tick the following information to show that you have understood what is involved and sign below to give your consent to take part in walking tutorials.

Please tick the boxes below to show that you have understood the elements of a walking tutorial:

\begin{tabular}{|c|l|}
\hline 1. $\square$ Participation is entirely voluntary. & $\begin{array}{l}\text { 7. } \square \text { In case of any problem during the } \\
\text { walking tutorial tutors will carry a mobile } \\
\text { phone. }\end{array}$ \\
\hline $\begin{array}{l}\text { 2. } \square \text { The route has already been selected by } \\
\text { tutors and assessed to be of a suitable } \\
\text { distance and free of serious hazards. }\end{array}$ & $\begin{array}{l}\text { 8. } \square \text { Students have to take responsibility } \\
\text { for being appropriately attired for a } \\
\text { walking tutorial. }\end{array}$ \\
\hline $\begin{array}{l}\text { 3. } \\
\text { beginning of a tutorial if they do not feel } \\
\text { able to participate for any reason. }\end{array}$ & $\begin{array}{l}\text { 9. } \square \text { Walking tutorials can only take place } \\
\text { if both the student and the tutor are in } \\
\text { agreement that this would be beneficial to } \\
\text { the student }\end{array}$ \\
\hline $\begin{array}{l}\text { 4. } \square \text { Tutors or students may choose to record } \\
\text { the walking tutorial. Tutors will only record } \\
\text { the tutorial for the purpose of record } \\
\text { keeping. Any recording made by students } \\
\text { may not be shared with others through any } \\
\text { medium. }\end{array}$ & $\begin{array}{l}\text { 10. } \square \text { Before leaving the Student Support } \\
\text { Centre the student and tutor will spend } \\
\text { some time setting objectives for the } \\
\text { walking element of the tutorial. }\end{array}$ \\
\hline $\begin{array}{l}\text { 5. Before leaving the Student Support } \\
\text { Centre for a walking tutorial tutors will } \\
\text { inform the Reception team that they are } \\
\text { leaving the building, and when they return. }\end{array}$ & $\begin{array}{l}\text { 11. } \square \text { On retuming to the Student } \\
\text { spend some time reviewing what was } \\
\text { discussed and completing related } \\
\text { activities. }\end{array}$ \\
\hline $\begin{array}{l}\text { 6. Walking tutorials can only take place } \\
\text { when the weather is suitable. }\end{array}$ & $\begin{array}{l}12 \text {. } \square \text { Although tutorials will take place in } \\
\text { public areas of campus every effort will be } \\
\text { made to maintain confidentiality. }\end{array}$ \\
\hline
\end{tabular}

I understand what a "LET walking tutorial" entails and give my consent to take part.

Student Name:

Signature:

Date: 


\section{References}

Aked, J., Marks, N., Cordon, C. \& Thompson, S. (2008). Five ways to wellbeing. London: New Economics Foundation.

Badenhorst, C., Moloney, C., Rosales, J. \& Dyer, J. (2016). Thinking through play: "Visual" approaches to post/graduate research writing. In Badenhorst, C. \& Guerin, C. (Eds.), Research literacies and writing pedagogies for Masters and Doctoral writers. (pp.335- 355). doi: 10.1163/9789004304338_019

Barnett, R. (2016). A will to write. New Vistas Journal, 2(1), 4-9. Retrieved from http://www.uwl.ac.uk/research/new-vistas-journal/volume-2-issue-1.

Bowstead, H. (2009). Teaching English as a foreign language- a personal exploration of language, alienation and academic literacy. Journal of Learning Development in Higher Education, 1, 1-10. Retrieved from http://www.aldinhe.ac.uk/ojs/index.php?journal=jldhe\&page=article\&op=view\&path\%5B $\%$ $\underline{5 \mathrm{D}=14}$.

Buckley, C.A. \& Waring, M.J. (2013). Using diagrams to support the research process: Examples from grounded theory. Qualitative Research, 13(2), 148- 172. doi:

$10.1177 / 1468794112472280$

Campbell, H. (2017, December 12). Pilates/yoga and helping students write [Blog Post]. Retrieved from https://doctoralwriting.wordpress.com/

Clughen, L. (2014). 'Embodied writing support': the importance of the body in engaging students with writing. Journal of Writing in Creative Practice, Intellect, 7 (2), 283-300. doi: 10.1386/jwcp.7.2.283_1

Corrigan, P. (2017, May 31). Your body is as important as your mind [Blog post]. Retrieved from https://thesiswhisperer.com/2017/05/31/8272/.

Creme, P. \& Lea, M.R. (2008). Writing at university. Maidenhead: Open University Press.

Csikszentmihalyi, M. (2014). Flow and the foundations of positive psychology: The collected works of Mihaly Csikszentmihalyi. doi:10.1007/978-94-017-9088-8

De Koven, B. (2017, February 15). Play in higher education. [Talk] Play Remix Summit. Coventry University.

Doyle, T. \& Zakrajsek, T. (2013). The new science of learning: how to learn in harmony with your brain. Virginia: Stylus Publishing.

Elbow, P. (2012). Vernacular eloquence. New York: Oxford University Press. 
Volume 28, 2018

http://journals.sfu.ca/cjsdw

Finer, B. S., Shelly, L., Gatta, O., Warmington, R. \& Alawdat, M. (2016). Low-tech tools as episteme: Rethinking student engagement in the writing process and beyond. Journal of Pedagogic Development, 6 (1), 54-61. Retrieved from http://uobrep.openrepository.com/uobrep/handle/10547/603526.

Franklin, D. (2017, January 9). Managing the \#phd- reMIND me [Blog post]. Retrieved from https://patthomson.net/tag/donna-franklin .

Gani, A. (2016, March 13). Tuition fees have "led to a surge in students seeking counselling'. The Guardian. Retrieved from https://www.theguardian.com/education/2016/mar/13/tuitionfees-have-led-to-surge-in-students-seeking-counselling.

Haas, S. (2014). Writer development made accessible! Brookes eJournal of Learning and Teaching, 6(2). Retrieved from http://bejlt.brookes.ac.uk/shortarticle/writer-developmentmade-accessible/.

Hattie, J. (2012). Visible learning for teachers. Abingdon: Routledge.

Huerta, M., Goodson, C., Beigi, M., \& Chulup, D. (2016). Graduate students as academic writers: Writing anxiety, self-efficacy and emotional intelligence. Higher Education Research and Development, 36(4) 1- 14. doi: 10.1080/07294360.2016.1238881

Hyerle, D. (2008). Thinking maps: Visual tools for activating habits of mind. In Costa, A.L. (Ed.), Learning and leading with habits of mind: 16 essential characteristics for success (pp. 149174). Alexandria: ASCD.

Ingold, T. (2010). Footprints through the weather-world: Walking, breathing, knowing. The Journal of the Royal Anthropological Institute, 16(1) 121-39. doi: 10.1111/j.14679655.2010.01613.x

James, A. (2013). LEGO® Serious Play®: A three-dimensional approach to learning development. Journal of Learning Development in Higher Education, 6, 1-18. Retrieved from http://www.aldinhe.ac.uk/ojs/index.php?journal=jldhe\&page=article\&op=view\&path\%5B $\%$ $\underline{\mathrm{D}=208}$.

Lakoff, G. \& Johnson, M. (1980). Metaphors we live by. Chicago, London: University of Chicago Press.

Lumau, K. (2012, September 5). The mental health crisis on campus: Canadian students feel hopeless, depressed, even suicidal. Maclean's Magazine. Retrieved from: http://www.macleans.ca/education/uniandcollege/the-mental-health-crisis-on-campus/

Marsh, S. (2017, May 23). Number of university dropouts due to mental health trebles. The Guardian. Retrieved from https://www.theguardian.com/society/2017/may/23/numberuniversity-dropouts-due-to-mental-health-problems-trebles 
Canadian Journal for Studies in Discourse and Writing/Rédactologie

Volume 28, 2018

http://journals.sfu.ca/cjsdw

McNiff, J. (2013). Action Research. London: Routledge.

Mental Wellbeing in Higher Education (2015). Student mental wellbeing in Higher Education:

Good practice guide. London: Universities UK. Retrieved from

http://www.universitiesuk.ac.uk/policy-and-analysis/reports/Documents/2015/studentmental-wellbeing-in-he.pdf .

Mewburn, I. (2015, February 25). Thesis prison [Blog post]. Retrieved from https://thesiswhisperer.com/2015/02/25/thesis-prison/.

Murray, R. (2014). Writing in social spaces: A social processes approach to academic writing. London: Routledge.

Nerantzi, C., \& McCusker, S. (2014, April 28-9). A taster of the LEGO® Serious Play® method for higher education. OER14 Building Communities of Practice Conference Proceedings, Newcastle, $U K$. Retrieved from

https://www.academia.edu/7817328/A_taster_of_the_LEGO_R_Serious_Play_R_method_LSP_ for_higher_education

Oppezzo, M. \& Schwartz, D. (2014). Give your ideas some legs: the positive effect of walking on creative thinking. Journal of Experimental Psychology: Learning, Memory, and Cognition, 40(4), 1142-1152. doi: 10.1037/a0036577

Race, P. (2015). The lecturer's toolkit. Abingdon: Routledge.

Rawle, F. (2017) Thinking outside the office. The National Teaching \& Learning Forum, Vol. 26, No. 4. doi: $10.1002 /$ ntlf.30116

Ridley, D. (2008) The Literature Review. London: Sage Study Skills.

Sword, H. (2017). Air \& light \& time \& space. Massachusetts: Harvard University Press.

Thomson, P. (2016, September 1). Academic writing- no one best way [Blog post]. Retrieved from https://patthomson.net/2016/09/01/academic-writing-no-one-best-way/.

Wellington, J., Bathmaker, A., Hunt, C., McCulloch, G. \& Sikes, P. (2005). Succeeding with your doctorate. London: Sage.

Wenger, C. (2015). Yoga minds, writing bodies: Contemplative writing pedagogy. Perspectives on Writing. Fort Collins, Colorado: The WAC Clearinghouse and Parlor Press. 